\title{
THERMOELECTRIC REFRIGERATOR WITH PATTERNED AIR FLOW ARRANGEMENT
}

\author{
Rakesh Sharma $\mathbf{V}^{\mathbf{1}}$, Deepak $\mathrm{K}^{\mathbf{2}}$ \\ ${ }^{1}$ Research Scholar, Department of Mechanical Engineering, Vardhaman College of Engineering, Hyderabad, India \\ ${ }^{2}$ Professor, Department of Mechanical Engineering, Vardhaman College of Engineering, Hyderabad, India
}

\begin{abstract}
In the present world, refrigeration systems produce cooling effect using refrigerants and release harmful hydro fluorocarbons into environment. Using such refrigerants higher output can be achieved but one of the major disadvantages is harmful gas emission and global warming. Such problems are not present in thermoelectric modules and do not pollute the environment. This work deals with the design of a thermoelectric refrigerator with an effort to improve performance by designing patterned air flow management system. A thermoelectric refrigerator prototype has been built and performance analysis has been carried out in controlled ambient condition $\left(25^{\circ} \mathrm{C}\right)$. A sheet metal enclosure with vents for creating patterned air flow is designed in solid works and fabricated. The proposed refrigerator with patterned air flow arrangement could achieve up to $5^{\circ} \mathrm{C}$ refrigeration temperature inside the cabinet. The comparative study revealed reduction of power consumption by $6.31 \%$ due to the changes made in the air flow pattern. CFD Analysis has been performed to validate the experimental results.
\end{abstract}

\section{Keywords: Thermoelectric Cooling, Peltier Refrigerator, Cooling System, Patterned Air Flow}

\section{INTRODUCTION}

Conventional refrigerators used in homes and industries depend on refrigerants such as R140, R434 consists of hydro fluorocarbons which are a threat to the ozone layer. Hence thermoelectric or Peltier refrigerator is best suitable for above requirements. Thermoelectric refrigerators are environment friendly, compact and affordable. Thermoelectric refrigerators are semiconductor based devices. They have got several advantages like solid construction, quiet \& reliable operation, no CFC's, precise temperature control. Since the air flow on both sides of electrical module affects the performance and inside temperature of unit, a great care must be taken during the design of sheet metal enclosures for effective air flow in both inside and outside of unit.

Scope of the project is to design a Peltier refrigeration system with sheet metal enclosure for patterned air flow both inside and outside of unit. Sheet metal enclosures are designed considering the general design considerations. Two sheet-metal enclosures both outside and inside of unit to produce patterned air flow on to the Peltier module have been designed. Two fans are arranged on both hot and cold side of Peltier module to extract the heat and cold from module respectively. The refrigerator performance has been analyzed with patterned air flow and without patterned air flow arrangements.

An experimental model was developed concentrating on heat sink design criteria and the model achieved cooling power of 50W [1]. A refrigerator using different TEC modules were built that achieved COP of 0.65[2]. Thermoelectric effect driven by solar power has been conducted [3].Comparison studies of thermoelectric and
VCRC units were performed [4].Comparison study of COP for the rmoelectric and VCRC were performed [5].Study on effect of thermo syphon on heat dissipation was performed [6].A thermoelectric module with heating as well as cooling application was designed [7]. The Study of thermoelectric materials was conducted [8].Compact cooling air conditioners were designed with thermoelectric principle [9]. Thermoelectric cooling for cars was presented [10]. Study of performance of multiple thermoelectric materials was conducted [11]. Study on green refrigeration concepts were performed [12]. Experiment for cheapest heat sink design was conducted [13].

The literature survey reveals that most of the works have been carried out on heat sink designs and different thermoelectric materials. Since the analysis of the Peltier refrigeration system with patterned air flow arrangement is not present in the above literature, this work focuses on the air flow management of the system. Three different air flow patterns have been designed and analyzed. The arrangement which achieved least refrigeration temperature has been considered for further analysis. The patterned air flow has been arranged with the help of sheet-metal enclosure.

\section{DESIGN AND EXPERIMENTAL SETUP}

The outer and inner sheet-metal enclosures for creating patterned air flow in the exhaust system have been designed. Sheet-metal enclosures are developed in Solid Works software and then fabricated. Figure 1 shows the image of enclosure that has been assembled to the setup. The experimental setup has been arranged using polystyrene cabinet of 3.6 cubic feet size with the Peltier module and exhaust system assembled on the top. The refrigerator is placed inside an air condition controlled roomat $25^{\circ} \mathrm{C}$. A 
hole has been made to the cabinet to accommodate the heat sink and Peltier module. 4 fans (CFM 75) are used in the exhaust system. One fan is used for internal air circulation and the other three for external air circulation. A power supply of $120 \mathrm{~V}$ is used as the source and harness is used for connections.

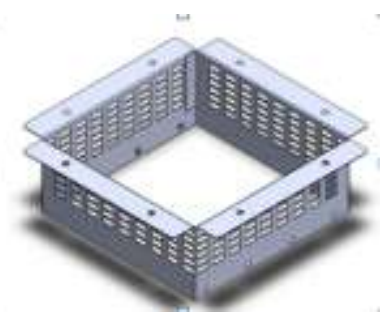

Fig.1 Sheet metal enclosure for creating patterned air flow

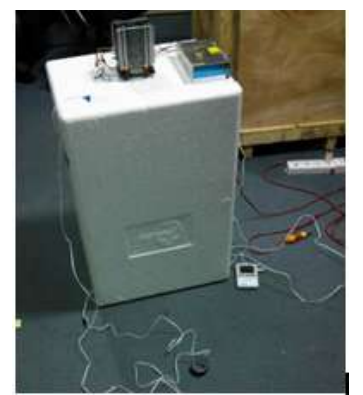

Fig.2 Refrigerator cabinet

\section{PERFORMANCE ANALYSIS}

The refrigerator is set in a controlled ambient condition and power supply has been given. The unit ran with patterned air flow and without patterned air flow till it achieved lower temperatures up to $5^{\circ} \mathrm{C}$. 2 Fans were used in the exhaust system to circulate the hot and cold air in the cabinet. The power consumption and time taken to reach temperatures are documented and the CFD analysis has been performed using ANSYS Work bench to check the maximum and minimum temperatures of the unit numerically. The boundary conditions wereset. Numerical simulations were conducted using ANSYS Workbench 17.2. A second order upwind scheme was used to convert governing equations of momentum and energy to algebraic ones by integration of the governing equations and using the applicable numerical schemes on the control volumes. The coefficient of performance of the thermoelectric refrigerator is determined by following equations:

$$
\begin{aligned}
& \mathrm{Qc}=\mathrm{I} \alpha \mathrm{Tc}-0.5 \mathrm{I} 2 \mathrm{R}-\mathrm{Kt}(\mathrm{Th}-\mathrm{Tc}) \\
& \mathrm{Q}_{\mathrm{h}}=\mathrm{I} \alpha \mathrm{Tc}+0.5 \mathrm{I} 2 \mathrm{R}-\mathrm{Kt}(\mathrm{Th}-\mathrm{Tc})
\end{aligned}
$$

Where,

$\mathrm{Q}_{\mathrm{h}}=$ Heat rejection from Peltier Hot side

$\mathrm{Qc}=$ Heat absorption into Peltier Cold side

$\alpha=$ See beck coefficient $\left(\mathrm{VK}^{-1}\right)$

$$
\begin{aligned}
\mathrm{I} & =\text { Current }(\mathrm{A}) \\
\mathrm{R} & =\text { Electrical Resistance of TEC (Ohms) } \\
\mathrm{K} & =\text { Thermal conductivity }
\end{aligned}
$$

The values of TEC 12715 have been considered

$$
\begin{gathered}
C O P=\frac{Q_{C}}{Q_{h}-Q_{C}} \\
=\frac{\left[I \alpha T_{c}-0.5 I^{2} R-K_{t}\left(T_{h}-T_{c}\right)\right]}{\alpha \mathrm{I}\left(T_{h}-T_{c}\right)+I^{2} R}
\end{gathered}
$$

Table -1: Peltier module data and temperature readings

\begin{tabular}{|c|c|c|}
\hline Parameter & General Air flow & Patterned air flow \\
\hline $\mathrm{I}$ & 12 & 11 \\
\hline$\alpha$ & 0.0532 & 0.0532 \\
\hline $\mathrm{T}_{\text {hot }}$ & 320 & 310 \\
\hline $\mathrm{T}_{\text {cold }}$ & 270 & 267 \\
\hline $\mathrm{R}$ & 0.866 & 0.866 \\
\hline $\mathrm{K}_{\mathrm{t}}$ & 1.233 & 1.233 \\
\hline $\mathrm{T}_{\mathrm{h}}-\mathrm{T}_{\mathrm{c}}$ & 50 & 36 \\
\hline
\end{tabular}

\section{RESULTS AND DISCUSSION}

The experimental observations are tabulated and the results are calculated. The current and voltage values are noted and power consumed by the refrigerator to reach to the refrigeration temperature up to $-5^{\circ} \mathrm{C}$ has beencalculated. Table 2 and 3 shows the results of experimental analysis.

Table -2: Power consumption - without patterned air flow

\begin{tabular}{|c|c|c|}
\hline Current $(\mathrm{A})$ & Voltage $(\mathrm{V})$ & Power $(\mathrm{W})$ \\
\hline 0.46 & 1.43 & 0.65 \\
\hline 0.76 & 2.54 & 1.93 \\
\hline 1 & 3.1 & 3.1 \\
\hline 1.24 & 4.47 & 5.54 \\
\hline 1.32 & 5 & 6.6 \\
\hline 1.56 & 7.3 & 11.38 \\
\hline 1.59 & 7.5 & 11.92 \\
\hline 1.63 & 8.2 & 13.36 \\
\hline 1.69 & 11.8 & 19.94 \\
\hline
\end{tabular}

Table -3: Power consumption - with patterned air flow

\begin{tabular}{|c|c|c|}
\hline Current $(\mathrm{A})$ & Voltage $(\mathrm{V})$ & Power $(\mathrm{W})$ \\
\hline 0.41 & 1.42 & 0.58 \\
\hline 0.72 & 2.52 & 1.81 \\
\hline 0.99 & 3 & 2.97 \\
\hline 1.22 & 4.46 & 5.44 \\
\hline 1.29 & 5 & 6.45 \\
\hline 1.50 & 7.2 & 10.80 \\
\hline 1.54 & 7.4 & 11.39 \\
\hline 1.60 & 8.1 & 12.96 \\
\hline 1.61 & 11.6 & 18.676 \\
\hline
\end{tabular}

Considering the values from the experimental data, $\mathrm{COP}-$ for normal air flow $=0.308$ $\mathrm{COP}-$ for Patterned air flow $=0.391$ 


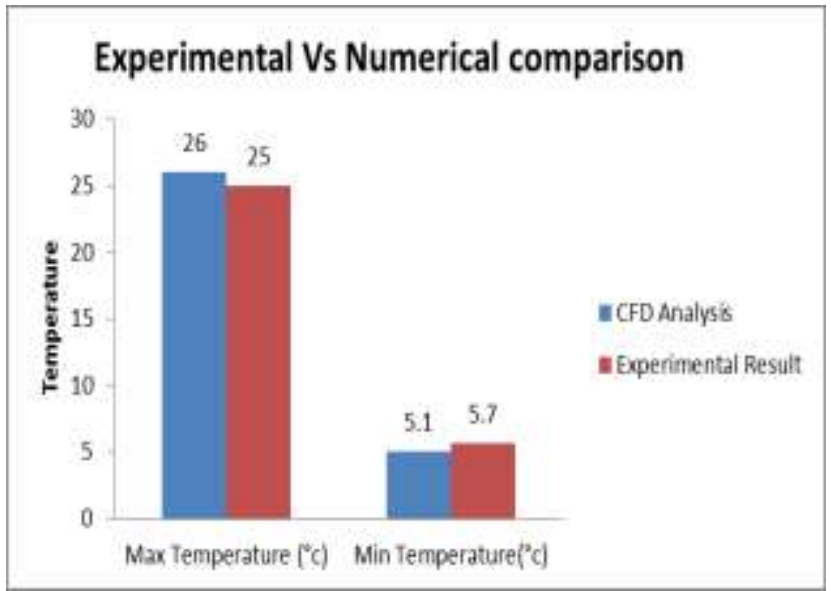

Fig.3: Experimental Vs Numerical data

The above graphs show that there is a deviation in experimental values when compared with the numerical analysis. This deviation might be because of the assumptions made in software and losses in practical environment.

\section{Time Vs Temperature}



Fig.4: Variation of Temperature with Time inside cabinet

Figure 4 shows the temperature variation with time inside the Peltier cabinet. From ambient condition of $25^{\circ} \mathrm{C}$, the system takes $25 \mathrm{~min}$ to reach $5^{\circ} \mathrm{C}$ temperature. The ambient condition is maintained by using an air conditioner

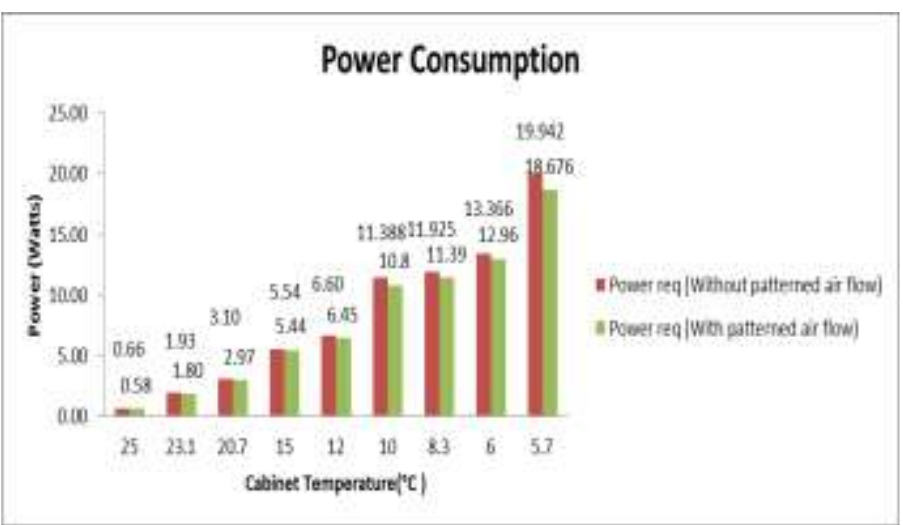

Fig. 5: Power consumption comparison - with and without patterned air flow
Figure 5 shows the difference in the power consumption of the Peltier refrigerator with metal enclosure and without the metal enclosure. The observations clearly state that the refrigerator with enclosure needs $1.26 \mathrm{~W}$ less to obtain $5^{\circ} \mathrm{C}$ temperature in the cabinet. Statistically, we can state that $6.3 \%$ of energy consumption is reduced by the modification

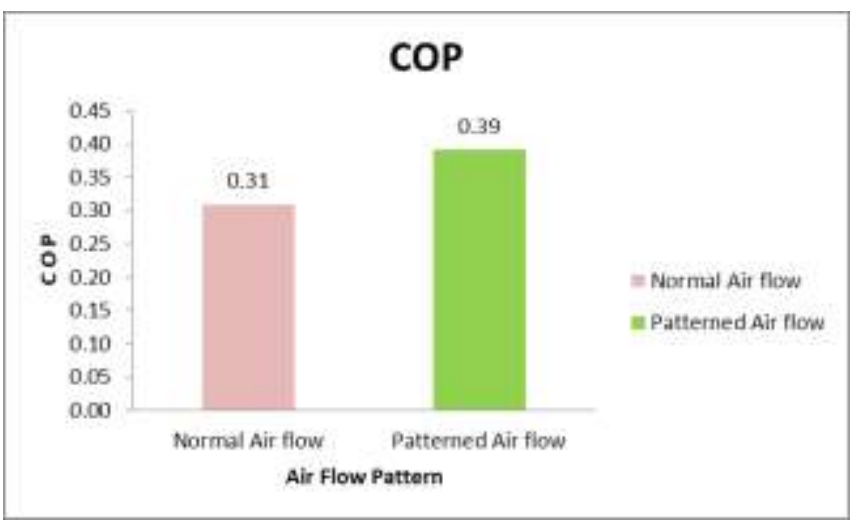

Fig.6: COP variation with air flow

There is a slight increase in COP of the thermoelectric refrigerator with the patterned air flow system which is depicted in Figure 6.

\section{CONCLUSION}

The following are the conclusions derived from the analysis:

- Patterned air flow arrangement (Exhaust and intake) improves performance of the thermoelectric refrigerator.

- Up to $6.31 \%$ of energy consumption can be reduced for the same refrigerator by regulatingthe air flow.

- COP of 0.39 is achievable withthermoelectric refrigerator with patterned airflow arrangement.

- Refrigeration temperatures as low as $5^{\circ} \mathrm{C}$ can be achieved using the thermoelectric modules.

- Air flow system is crucial in a thermoelectric refrigerator.

- Low noise refrigerators can be developed using Peltier technology.

- Better insulation to the unit helps in retaining the low temperatures for more duration.

\section{ACKNOWLEDGEMENT}

Though I have put my efforts in this research work, it would not have been possible without the kind support from the management of Vardhaman College of Engineering. I would like to thank all of them who have helped me directly or indirectly in completing this work.

\section{REFERENCES}

[1] MatthieuCosnier,MatthieuCosnier, Gilles Fraisse, LingaiLuo, An Experimental and Numerical Study of a Thermoelectric Air-Cooling and Air-Heating System, International Journal of Refrigeration, 31(6), 1051-1062, (2008). 
[2] SuwitJugsujinda, AthornVora-ud, TosawatSeetawan,Analyzing of Thermoelectric Refrigerator Performance, Procedia Engineering, 8, 154-159, (2011).

[3] Alemi. H, Aghanajafi. C and Kashi. A, Optimization and Investigation of Multi-Stage Thermoelectric Generation Systems with Particle Swarm Optimization (PSO), Electrical and Electronics Engineering: An International Journal (ELELIJ), 3(2), (2014)

[4] Riffatand Guoquan.- Comparative Investigation of Thermoelectric Air-Conditioners versus Vapor Compression and Absorption Air-Conditioners, Journal of Applied Thermal Engineering, 24 , 19791993,(2004).

[5] Riffat and Qiu., Design and Characterization of a Cylindrical Water Cooled Heat Sink for Thermoelectric Air-Conditioners. International Journal of Energy Research, 30, 67-80,(2005)

[6] Astrain D., Vian J.G., \& Dominguez M., Increase of COP in the Thermoelectric Refrigeration by the Optimization of Heat Dissipation. Applied Thermal Engineering, 23, 2183-2200,(2003).

[7] Shen.Xiao. Chen \& Wang., Investigation of a Novel Thermoelectric Radiant Air-Conditioning System. Journal of Energy and Buildings, 59, 123-132,(2012)

[8] Virjoghe., Diana., Marcel \& Florin., Numerical Simulation of Thermoelectric System - Latest trends on Systems, 15(2), 630-635,(2009).

[9] Maneewan., Tipsaenpromand Lertsatitthanakorn., Thermal Comfort Study of a Compact Thermoelectric Air Conditioner. Journal of Electronic Materials, 39(9), 1659-1664, (2010).

[10] Manoj S., \&Walke., Thermoelectric Air Cooling for Cars. International Journal of Engineering Science and Technology, 40(5), 2381-2394,(2011).

[11] Yadavand Nirves., Review on Thermoelectric Materials And Applications. International Journal for Scientific Research \& Development, 1,413417,(2013).

[12] Manoj Kumar., Chattopadhyay and Neogi., A Review on Developments of Thermoelectric Refrigeration And Air Conditioning Systems:A Novel Potential Green Refrigeration and Air Conditioning Technology. International Journal of Emerging Technology and Advanced Engineering, 38,362-367, (2013).

[13] Huang B., Chin C.J., and Duang C.L., A Design Method of Thermoelectric Cooler. International Journal of Refrigeration, 23,208-218,(1999).

\section{BIOGRAPHIES}

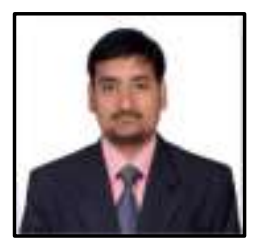

V.Rakesh Sharma is a Research Scholar, Department of Mechanical Engineering, Vardhaman College of Engineering, and Hyderabad, India. Graduated in Mechanical engineering from Kakatiya university campus in 2013. Currently working as a senior Project manager in a refrigerator manufacturing company.

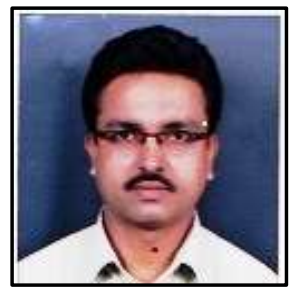

K. Deepak is currently working as Professor in Mechanical Engineering at Vardhaman College of Engineering, Hyderabad, India. and his subjects include Thermodynamics, Fluid Mechanics, Thermal Engineering, Refrigeration and AirConditioning and Heat Transfer. He is a life member of Indian Society for Technical Education and The Institution of Engineers (India). He has more than 19 papers in diverse fields to his credit. 